\title{
КЛИНИЧЕСКИЙ ФЕНОТИП И МОЛЕКУЛЯРНО-ГЕНЕТИЧЕСКИЕ ВАРИАНТЫ В КОГОРТЕ ПАЦИЕНТОВ С НАРУШЕНИЕМ ФОРМИРОВАНИЯ ПОЛА
}

\author{
Никитина И.Л., Саракаева Л.Р., Костарева А.А., Кудряшова Е.К.
}

\begin{abstract}
Федеральное государственное бюджетное учреждение «Национальный медицинский исследовательский центр им. В.А. Алмазова» Минздрава России, Санкт-Петербург, Россия
\end{abstract}

Актуальность. Нарушения формирования пола (НФП) относятся к группе редких врожденных аномалий, которые характеризуются несоответствием генетического, гонадного, фенотипического и психологического пола. Диагностика и планирование оказания помощи требуют комплексного подхода и должны осуществляться мультидисиплинарной группой специалистов.

Цель. Изучение ассоциаций выявленных генетических вариантов с клиническими проявлениями в когорте пациентов с нарушением формирования пола.

Пациенты и методы. В исследование были включены 28 пациентов с клинически верифицированным диагнозом НФП с кариотипом 46ХУ. Всем пациентам проведено молекулярно-генетическое исследование методом таргетного секвенирования нового поколения (NGS), на приборе MiSeq (платформа Illumina). Для данного исследования была разработана панель генов HaloPlex (Agilent), включающая в себя кодирующие области следующих 80 генов-кандидатов, ассоциированных с НФП. Выявленные варианты затем были проверены секвенированием по Сенгеру. Биоинформационный анализ проводился с использованием баз ОМIM, «1000 genomes», ESP6500, Genome Aggregation Database projects. Генетические варианты классифицированы в соответствии с рекомендациями Американского колледжа медицинской генетики и геномики (ACMG).

Результаты. Генетические варианты, оцененные, как вероятно патогенные, патогенные и неизвестной значимости были выявлены у $39 \%$ пациентов с НФП. В ассоциации с клиническим фенотипом нарушения половой дифференцировки они были расценены, как каузативные. В $82 \%$ случав выявлено не более 1 вероятно патогенного варианта, в 18\% - два таких варианта, что свидетельствовало об олигогеном генезе НФП. 43\% среди выявленных генетических вариантов отнесены к ранее неописанным. В ассоциации с клиническим фенотипом варианты в гене NR5A1 выявлены у двух пациентов с гонадным дисгенезом; в гене MAP3K1 - у других двоих пациентов также с гонадным дисгенезом. Мутации в гене $A R$ были представлены полной резистентностью к андрогенам у троих пациентов. Вариант в гене $M A M L D 1$ имел место у пациента с проксимальной формой гипоспадии; в гене CYP17A1 - при редкой форме врожденной гиперплазии коры надпочечников - дефиците фермента 17-альфа гидроксилазы. У двоих пациентов имел место олигогенный генез НФП. У одного представлен мутациями в генах MAP3K1 и MAMLD1 с клиническим фенотипом промежностной гипоспадии, у второго - мутациями в генах AR и SEMA3A, что клинически было представлено парциальной формой резистентности к андрогенам и явилось основанием для смены пола воспитания на женский. Оба случая вариантов в гене стероидогенного фактора NR5A1 были представлены семейными формами.

Выводы. Включение в спектр обследования при НФП секвенирования нового поколения с использованием таргетных панелей генов улучшает понимание генетических основ нарушений половой дифференцировки, что в ряде случаев также оказывает влияние на коррекцию терапии и присвоение паспортного пола воспитания.

КЛЮЧЕВЫЕ СЛОВА: нарушения формирования пола (НФП); секвенирование нового поколения; дисгенезия гонад; полная резистентность к андрогенам; парциальная резистентность к андрогенам; нарушения биосинтеза андрогенов; паспортный пол 